\title{
Counterproductive Behaviors in State Hospitals: A Review of the Role of Organizational Cynicism and Injustice
}

\author{
Abdi, Parisa \\ Master in Public Management, Tarbiat Modares University, Tehran, Iran \\ Delkhah, Jalil \\ Assistant Professor, Management and Technology Development Center, Tarbiat Modares University, Tehran, Iran \\ Corresponding Author Email: j.delkhah@modares.ac.ir \\ Kheirgoo, Mansour \\ Faculty Member, Imam Ali University, Tehran, Iran
}

\section{Doi:10.5901/mjss.2016.v7n4s1p196}

\begin{abstract}
Researchers have shown that organizational civic and citizenship behaviors are being declined while hostile and counterproductive behaviors and interactions are getting increased. Counterproductive behaviors include a wide range of behaviors like impoliteness, being carefree, theft and aggressive behaviors. The fact is that counterproductive behaviors, in employees' organizational life, are increasingly on the rise. However, counterproductive behaviors and interactions at workplace are troublesome because those who commit counterproductive behaviors constantly interact with their target individuals and, subsequently, cause a great deal of negative interactions in the organization. The purpose of current study was to investigate the effect of organizational cynicism and injustice on counterproductive behaviors of personnel in state hospitals. The present study was an applied and descriptive-survey research. Confirmatory Factor Analysis Model and Lisrel 8.5 have been used for hypotheses testing and achieving the results. The results of the present study showed that the increase of employees' organizational cynicism brings about their counterproductive behaviors in state hospitals. The rise of organizational injustice increases employees' counterproductive behaviors. Besides, the increase of organizational injustice rises employees' organizational cynicism in state hospitals.
\end{abstract}

Keywords: Organizational Cynicism; Organizational Injustice; Counterproductive Behavior, Hospital.

\section{Introduction}

Research on unethical behaviors of employees in different organizations and industries has a shorter history compared with positive, efficient and productive behaviors. Although certain types of negative and unethical behaviors at workplace have already been studied in solitary, the systematic and scientific study of such behaviors have recently been instigated. Studies have indicated that organizational civic and citizenship behaviors are declining while hostile and counterproductive behaviors and interactions are increasing. Counterproductive behaviors include a wide range of behaviors like impoliteness, being carefree, theft and aggressive behaviors. The fact is that counterproductive behaviors, in employees' organizational life, are increasingly on the rise. However, counterproductive behaviors and interactions at workplace are troublesome as those who commit counterproductive behaviors constantly interact with their target individuals; successively they cause a great deal of negative interactions in the organization (1).

Counterproductive and deviant behaviors is a common problem that approximately exists in all organizations specifically in both less developed and developing countries. Counterproductive behaviors lead to productivity reduction, rising costs, unaccomplished work, and are a damage to the status and reputation of the organizations (2).

Several research has shown that organizational cynicism can affect different factors influencing the success of an organization. Those who are cynic about the organization not only are less likely to show extra-role and citizenship behaviors but also are less committed and adaptive to the organization and its changes. Many of organizational leaders have figured out that cynical attitudes are problematic for them and the organization. So they have made many efforts to reduce cynicism (3). 
Numerous empirical evidences indicated the important role of justice in the proceedings and relations of employees within the organization. Many researchers believe that if the personnel perceive the unfair and biased organizational decisions or management actions, they will more likely feel resentment, outrage, anger and hostility. Some examples of reaction to injustice can be made and shown as a direct relationship between injustice and backbiting, theft and hostility (4).

The current study intended to investigate the effect of organizational cynicism and injustice on counterproductive behaviors of the employees in state hospitals, based on Conceptual Model and Framework (Figure2); as it seems that, in state hospitals, the most influential factor in the increase of cynicism amongst organizational employees can be traced back to injustice against them which has a direct impact on their performance and default.

\section{Concept of Counterproductive Behaviors}

Counterproductive behaviors or destructive behaviors refer to "the intentional behaviors that violate organizational norms and threaten the health of organization, employees or both" (5). Workplace deviance is intentional because the employees either are not inclined to adapt themselves to the expected norms or are motivated to violate the norms.

Spector and Fox (2005) have proposed that, in general, counterproductive behaviors include different deviant behaviors and actions tending to damage the organization and its stakeholders like the clients, colleagues and supervisors (6).

The researchers have defined and termed such behaviors differently like organizational deviance, antisocial behaviors, organizational misbehaviors, dysfunctional behaviors, workplace aggression and workplace deviance. In spite of all different definitions, there are some features common to them all (7).

\subsection{Features of Counterproductive Behaviors}

Robinson and Greenberg (1998) have introduced five definitions encompassing all counterproductive behaviors. They propose that all the current definitions have a perpetrator, intentionality, target, action and consequence.

First, all counterproductive behaviors have a perpetrator who is either inside or outside the organization. The majority of researchers have focused on the members inside the organization, those performing destructive behaviors.

Second, counterproductive behaviors, due to their destructive consequences, can be either intentional and conscious or unintentional or subconscious. Intentionality is an important factor to determine individuals' motivational behaviors. Spector and Fox (2005) state that destructive behaviors at workplace are deliberate because they are intentional whether or not the employees concern a harmful result. Although many researchers have concentrated on deliberate or intentional behaviors, Moberg (1977) suggest that sometimes counterproductive behaviors are subconscious and unintentional, so are their negative consequences. Therefore, people may follow destructive attitudes without knowing it.

Third, counterproductive behaviors require a specific target, Robinson and Greenberg (1998) categorize the targets into three groups, i.e. internal-external, personal-organizational and additional targets. The targets of destructive behaviors can be the members who work either inside or outside the organization. In addition, counterproductive behaviors may not only hurt the organization but also its inside members or even both. Counterproductive behaviors may have additional targets, such as clients, society, former colleagues, or stakeholder of the organization.

Fourth, counterproductive behaviors are represented as an act of deviation and violation which can differ in the range of publicity or violation of criteria. Neuman and Baron (1977) as well as Greenberg and Alge (1998) have divided the counterproductive behaviors into two groups of passive or active and verbal or physical based on Buss' classification of aggression (1961). Counterproductive behaviors can also differ in two cases; that is, whether or not they violate the organizational and social rules or even norms, and whether or not they are against the interests of organization.

Finally, counterproductive behaviors have some consequences. Most definitions of counterproductive behaviors have focused on the negative aspect of the behavior. Nevertheless, some researchers have recently proposed that counterproductive behaviors can result in some beneficial consequences like disobedience of unethical commands (7).

In line with the studies on destructive behaviors, considerations should be given to the fact that different forms of destructive or counterproductive behaviors are associated or almost positively correlated with each other. This has also been found not only in the research and rating scale of managers and extensive self-reporting of nurses but also in the studies in which one or more instances of counterproductive behaviors have been measured. Generally, it can be stated that all counterproductive behaviors share the same issue; that is, the violation of legitimate interests of an organization which are potentially detrimental to members or the entirety of the organization. Therefore, the following conditions are considered necessary to regard a behavior as a destructive behavior. 
- First Condition: A typical behavior must be an intentional action (relative to misfortune or unintentionality) regardless of its perceptible consequences. It must be noted that the motivation behind the behavior is crucial.

- Second Condition: The behavior must be potentially and predictably detrimental. Furthermore, the behavior does not necessarily cause an unacceptable outcome. That is, even if the behavior, at the moment of occurrence, does not bring about negative outcomes, it does not make sense not to consider it as a destructive behavior.

- Third Condition: The behavior must be in contrast with (violate) the legitimate and legal interests of employees and the organization even if it is not more crucial than the legitimate interests of the individuals and organizations.

\subsection{Types of Workplace Deviant Behaviors}

The typology of deviant behaviors of employees is important for the development of systematic studies. It helps us achieve a comprehensive theory about them. There are different categorizations of deviant behaviors; one of the most important of which classifies the workplace deviant behaviors into positive or constructive and negative or destructive behaviors.

Constructive Deviant Behaviors, including creative behaviors, intolerance with or criticism of incompetent supervisors, are intentional behaviors which improve the health of the organization and its members by violating organizational norms; as a result, they facilitate the achievement of organizational goals (9).

Destructive Deviant Behaviors, including theft and sabotage, are intentional behaviors which threaten the health of the organization and its members by violating the organizational norms.

The typology of negative deviant behaviors differs in two points i.e. "interpersonal-organizational" and "seriousminor." These two dimensions provide a dimensional graph which defines deviant behaviors in four quarters (Figure 1) namely production deviance, property deviance, political deviance and personal deviance (10).

\section{Organizational Cynicism}

Cynicism has been proposed as a new paradigm in worker-employer relationship and is the result of long working hour, hard working conditions and inefficient management and leadership (11). Generally, two important definitions have been introduced for organizational cynicism as follows:

Anderson (1996) define organizational cynicism as a general and specific attitude that is formed because of disappointment, frustration, negative feelings and mistrust towards the organization (12).

Organizational cynicism can be defined based on Expectancy Theory, Attribution Theory, Social Exchange Theory and Social Motivation Theory. That is, organizational cynicism refers to a negative attitude towards the organization; the belief that the organization lacks honesty; it is a negative feeling towards the organization; a tendency to contemptuous and disparaging behaviors towards the organization (12).

\subsection{Dimensions (Elements) of Organizational Cynicism}

Organizational cynicism has been defined as a negative attitude toward the organization and consists of three dimensions (11).

1. A belief that the organization does not have honesty.

2. A negative attitude toward the organization;

3. A tendency to contemptuous and disparaging behaviors toward the organization that are associated with the aforementioned beliefs and negative feelings.

\section{Organizational Justice}

In the literature of organization and management, the term organizational justice has been defined by Grinberg (1987). In his opinion, organizational justice is related to the employees' conception about work equity. He used this term to elaborate on the role of equity at workplace. Organizational justice infers the perception and feeling of equity and equality amongst employees and the relation it has with their behavior and communication at work. Organizational justice also refers to employees' understanding about the fairness of decisions inside an organization (13).

Organizational justice is a variable to describe the justice that is directly associated with work opportunities. In 
organizational justice the focus is especially on how to behave with employees to make them feel they are treated fairly.

Studies have shown that justice procedures play important roles in the organization and indicate how the employees are treated may influence their behavior, feeling, beliefs and also their attitudes. The employees are faced with at least two sources while justice is administered or violated. The most obvious and the first source is the supervisor or the manager. He has authority over the subordinates. He can influence important issues like increasing salaries or promoting job opportunities. The second source is the organization itself. Although the latter is subtler, it cannot be taken for granted.

Organizational justice leads to employees' higher commitments and their extra-role behavior. On the other hand, those who feel injustice at work are more probable to quit the job or demonstrate low levels of organizational commitment or even abnormal behaviors like revenge. So, figuring out how people judge equity and justice at work or how they respond to justice or injustice is considered as fundamental issues especially for understanding organizational behaviors (14).

\section{Research Model and Hypotheses}

The Conceptual Model and Framework is shown in Figure 1. The purpose of the current study was to investigate the effect of organizational cynicism and injustice on counterproductive behaviors of the employees in state hospitals based on a Conceptual Model and Framework (Figure2).

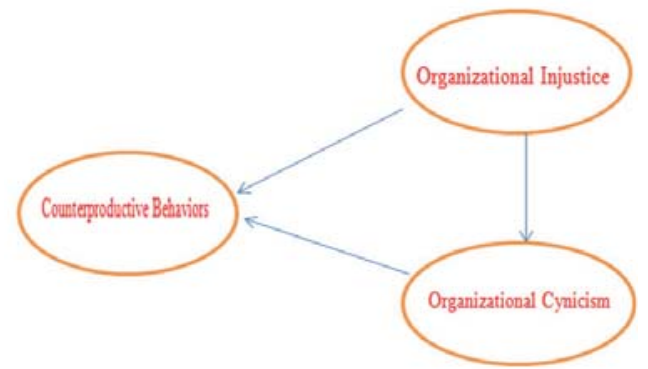

Figure 1: Research Conceptual Model and Framework. (Organizational Injustice, Counterproductive Behaviors, Organizational Cynicism )

The research hypotheses were developed based on the research Model:

1. Organizational cynicism has a significant effect on counterproductive behaviors.

2. Organizational injustice has a significant effect on counterproductive behaviors.

3. Organizational injustice has a significant effect on organizational cynicism.

\section{Organizational cynicism}

Conceptual Definition: Organizational cynicism is defined as a negative attitude towards the organization, and the belief in the lack of honesty in the organization. It includes frustration, disillusionment and negative attitudes towards the organization; the negative attitude is due to the negative experiences at work (15).

Operational Definition: The present study defines organizational cynicism as the difference between words and deeds, lack of honesty in the organization and being aggressive to the organization. Organizational cynicism, in the present study, was measured through the questions 1 to 18 of the questionnaire.

\section{Counterproductive Behaviors}

Conceptual Definition: Counterproductive behaviors are destructive behaviors intending to harm the organization or its members, including theft and passive behaviors like reluctance at work (4).

Operational Definition: In the current study counterproductive behaviors include improper working on purpose, taking appliances to home without permission, reluctance to going to work with the pretext of disease and some gossips about the organization. Organizational counterproductive behaviors, in the current study, were measured through the questions 19 to 36 of the questionnaire. 


\section{Organizational Injustice}

Conceptual Definition: Organizational injustice refers to the employees' conception about the inequity and inequality of decisions and its related process in an organization $(16,17)$.

Operational Definition: In the current study, organizational injustice refers to the unfairness (inequity) in employees' payments, bonuses, organizational procedures and also the managers' behavior. Organizational injustice, in the current study, was measured through the questions 37 to 54 of the questionnaire.

Many researches have been done in various fields but this field is less considered. $(18,1920,21,22,23,24,25$, $26,27)$

\section{Methodology}

As the purpose of current study was to investigate the effect of organizational cynicism and injustice on counterproductive behaviors in state hospitals, it is considered as an Applied and Descriptive-Analytical Research. The population consisted of 250 employees of a state hospital. Sample size included 152 individuals selected based on Morgan's Table. A questionnaire was used for data collection. The following table shows the questionnaire for each of the three main variables in the present study. The reliability of the research was tested using Cronbach's Alpha. The following table also displays the research variables of Cronbach's alpha. Notably, Cronbach's alpha coefficient was calculated in two stages, the pilot administration phase and final administration phase. To estimate the Cronbach's alpha coefficient at the pilot phase, a sample of 20 subjects (participants) has been chosen; accordingly, it was obtained over 0.70 using SPSS.15 based on the data analysis of preliminary sample, likewise, the Cronbach's Alpha coefficient for all all the variables of the questionnaire at the final administration phase was determined over 0.70 . Therefore, it can be concluded that the questions of the questionnaire have an acceptable reliability. To test research hypotheses, Confirmatory Factor Analysis Model was used.

Table 1: Questions related to variables and their reliability

$\begin{array}{lcccc}\text { Variable } & \text { Related Questions Number of Questions } & \text { Preliminary Cronbach's Alpha Final Cronbach's Alpha } \\ \text { Organizational Cynicism } & 1-18 & 18 & 0.914 & 0.951 \\ \text { Counterproductive Behaviors } & 19-36 & 18 & 0.757 & 0.923 \\ \text { Organizational Injustice } & 37-54 & 18 & 0.878 & 0.919\end{array}$

To measure the aforementioned three variables proposed in research conceptual model, confirmatory factor analysis was used (Figure $3 \& 4$ ). Confirmatory Factor Analysis is a technique to test the hypotheses of the theory, based on which the researcher commences his analysis with a presumption. CFA, that is based on a strong theoretical and empirical foundation, determines which variable correlates to which factor (Questions). Hereunder, the associated factors with each variable is discussed.

\section{Research Results}

\subsection{Description of Demographic Data}

Data shows that $\% 43.4$ and $\% 55.9$ of the respondents were respectively male and female.

In terms of age, \%7.2 of the participants aged 20 to 30 years, \%54.6 aged 31 to 40 years, \% 34.2 aged 41 to 50 years and $\% 2.6$ were above 50 years old.

In terms of ethnicity, \%44.1 of the participants were Fars, \%25.7 were Azari and Turk, $\% 1.3$ was Lor, $\% 2$ were Kurdish, \%12.5 were from North, \%10.5 were from South, and \%0.7 participated from other ethnic groups.

In terms of education, $\% 3.3$ of the participants held a diploma, $\% 9.2$ had associate degree, $\% 61.8$ held a bachelor degree, \%17.8 had a master degree, and \%5.9 were Ph.D. holders.

In terms of job experience, $\% 11.2$ of the personnel had been working in the hospital for less than 5 years, $\% 35.5$ had 5 to 10 years of experience, $\% 27$ had 11 and 15 years of experience, \%21.1 had 16 to 20 years, and \%5.3 had more than 20 years of experience

In terms of employment contract, \%40.8 of the personnel were official clerks, $\% 19.1$ were probationers, $\% 11.8$ were fixed-term staff, $\% 11.2$ were contractual employers, $\% 5.3$ freelancers and 11.8 percent were agency staff. 
In terms of payment, \%24.3 of the personnel were paid under 1.5 million, $\% 52$ from 1.5 to 2 million, $\% 15.1$ from 2 to 2.5 million, and \%6.6 earned more than 2.5 million.

In terms of occupation, $\% 3.3$ were faculty members, $\% 1.3$ were GPs, $\% 2.6$ were specialists, $\% 41.4$ were nurses, $\% 13.2$ were paramedical staff, $\% 20.4$ were administrative and support staff, and $\% 13.2$ was customer service staff.

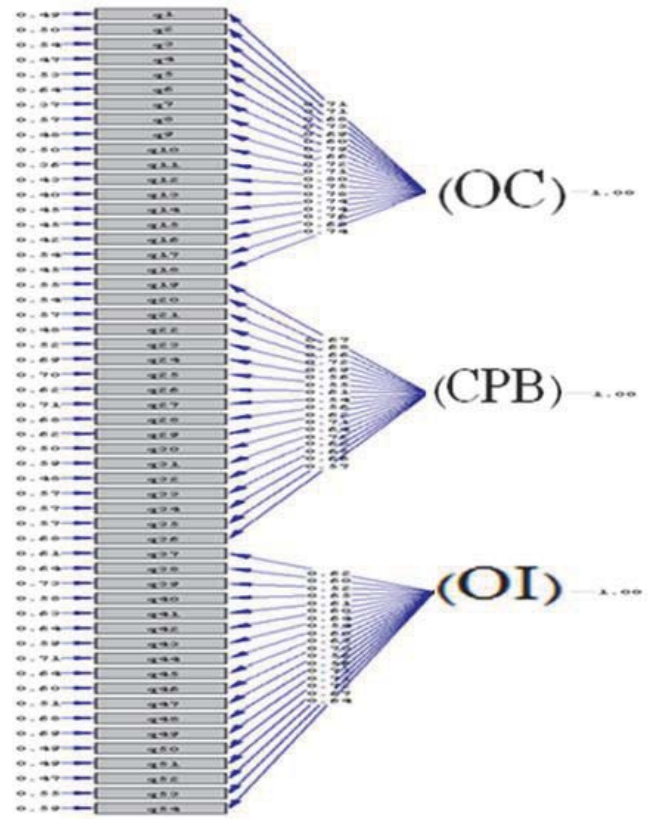

Figure 2: Confirmatory Factor Analysis (Standard Coefficients or Factor Loading)

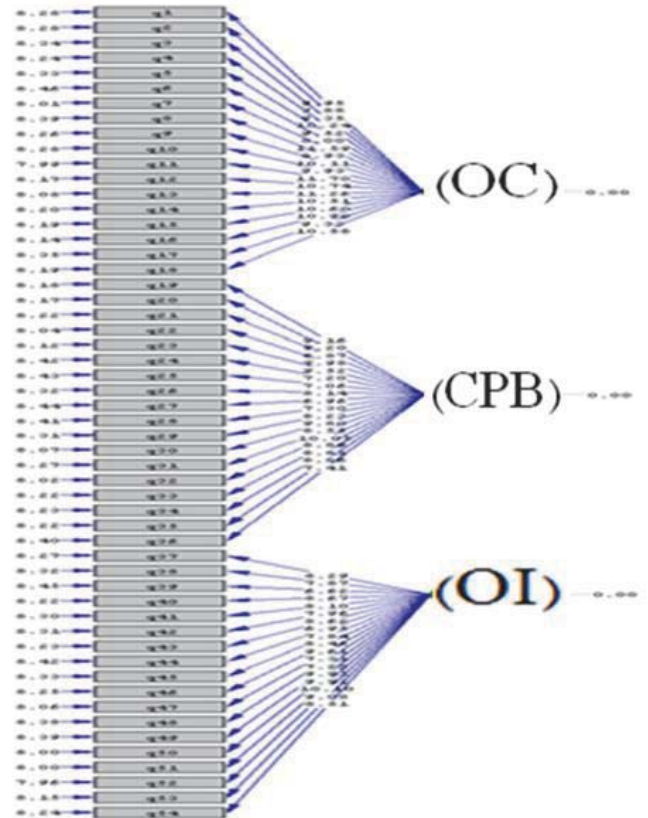

Figure 3: Confirmatory Factor Analysis Model (Significance Level or P-value) 


\subsection{First Variable: Organizational Cynicism}

Cynicism variable had 18 factors (questions/items). Table 2 presents the standard coefficient (factor loading), observed variance and P-value of each item. The factor loading of all questions had an acceptable P-value (higher than 1.96). Therefore, it can be concluded that all the questions of the questionnaire had an acceptable validity to measure their corresponding variables.

Table 2: The factors of the first variable: Organizational Cynicism

\begin{tabular}{|c|c|c|c|c|c|c|c|}
\hline Question & $\begin{array}{c}\text { Standard Coefficient } \\
\text { (Factor Loading) }\end{array}$ & Observed Variance & P-value & Question & $\begin{array}{c}\text { Standard Coefficient } \\
\text { (Factor Loading) }\end{array}$ & Observed Variance & P-value \\
\hline Q1 & 0.71 & 0.50 & 9.95 & Q10 & 0.71 & 0.50 & 9.93 \\
\hline Q2 & 0.71 & 0.50 & 9.88 & Q11 & 0.80 & 0.64 & 11.70 \\
\hline Q3 & 0.68 & 0.46 & 9.35 & Q12 & 0.75 & 0.56 & 10.74 \\
\hline Q4 & 0.73 & 0.53 & 10.24 & Q13 & 0.78 & 0.60 & 11.26 \\
\hline Q5 & 0.69 & 0.47 & 9.52 & Q14 & 0.74 & 0.54 & 10.51 \\
\hline Q6 & 0.60 & 0.36 & 8.00 & Q15 & 0.74 & 0.54 & 10.60 \\
\hline Q7 & 0.79 & 0.62 & 11.59 & Q16 & 0.76 & 0.57 & 10.90 \\
\hline Q8 & 0.66 & 0.43 & 8.93 & Q17 & 0.63 & 0.39 & 9.33 \\
\hline Q9 & 0.72 & 0.51 & 10.11 & Q18 & 0.74 & 0.54 & 10.58 \\
\hline
\end{tabular}

According to the observed variance of each factor, their relative significance can be realized as an index to measure their corresponding variables. As shown in Table 2, question 11 can be considered as a more significant index to measure organizational cynicism than other questions.

\subsection{Second Variable: Counterproductive Behaviors}

This variable also has 18 factors (questions/items). Table 3 displays the standard coefficient (factor loading), observed variance and P-value of each item.

Table 3: The factors of the second variable: Counterproductive Behaviors

\begin{tabular}{|c|c|c|c|c|c|c|c|}
\hline Question & $\begin{array}{c}\text { Standard Coefficient } \\
\text { (Factor Loading) }\end{array}$ & Observed Variance & P-value & Question & $\begin{array}{c}\text { Standard Coefficient } \\
\text { (Factor Loading) }\end{array}$ & Observed Variance & P-value \\
\hline Q19 & 0.67 & 0.44 & 9.16 & Q28 & 0.56 & 0.31 & 7.30 \\
\hline Q20 & 0.68 & 0.46 & 9.20 & Q29 & 0.62 & 0.38 & 8.23 \\
\hline Q21 & 0.66 & 0.43 & 9.87 & Q30 & 0.71 & 0.50 & 9.80 \\
\hline Q22 & 0.72 & 0.51 & 9.98 & Q31 & 0.64 & 0.40 & 8.55 \\
\hline Q23 & 0.69 & 0.47 & 9.52 & Q32 & 0.72 & 0.51 & 10.05 \\
\hline Q24 & 0.56 & 0.31 & 7.20 & Q33 & 0.66 & 0.43 & 8.89 \\
\hline Q25 & 0.55 & 0.30 & 7.06 & Q34 & 0.65 & 0.42 & 8.81 \\
\hline Q26 & 0.61 & 0.37 & 8.14 & Q35 & 0.65 & 0.42 & 8.86 \\
\hline Q27 & 0.54 & 0.29 & 6.96 & Q36 & 0.57 & 0.32 & 7.41 \\
\hline
\end{tabular}

According to Table 3, question 32 can be considered as a more significant index to measure counterproductive behaviors than other questions.

\subsection{Third Variable: Organizational Injustice}

This variable also has 18 factors (questions/items). Table 4 presents the standard coefficient (factor loading), observed variance and P-value of each item. 
Table 4: The factors of the third variable: Organizational Injustice

\begin{tabular}{|c|c|c|c|c|c|c|c|}
\hline Question & $\begin{array}{c}\text { Standard Coefficient } \\
\text { (Factor Loading) }\end{array}$ & Observed Variance & P-value & Question & $\begin{array}{c}\text { Standard Coefficient } \\
\text { (Factor Loading) }\end{array}$ & Observed Variance & P-value \\
\hline Q37 & 0.62 & 0.38 & 8.29 & Q46 & 0.63 & 0.39 & 8.45 \\
\hline Q38 & 0.60 & 0.36 & 7.87 & Q47 & 0.70 & 0.49 & 9.51 \\
\hline Q39 & 0.52 & 0.27 & 6.62 & Q48 & 0.56 & 0.31 & 7.31 \\
\hline Q40 & 0.65 & 0.42 & 8.67 & Q49 & 0.56 & 0.31 & 7.22 \\
\hline Q41 & 0.61 & 0.37 & 8.10 & Q50 & 0.71 & 0.50 & 9.91 \\
\hline Q42 & 0.60 & 0.36 & 7.96 & Q51 & 0.71 & 0.50 & 9.91 \\
\hline Q43 & 0.64 & 0.40 & 8.62 & Q52 & 0.72 & 0.51 & 10.10 \\
\hline Q44 & 0.64 & 0.40 & 6.95 & Q53 & 0.67 & 0.44 & 9.08 \\
\hline Q45 & 0.60 & 0.36 & 7.84 & Q54 & 0.64 & 0.40 & 8.51 \\
\hline
\end{tabular}

According to Table 4, question 52 can be considered as a more significant index to measure organizational injustice than other questions.

\section{Research Hypotheses Testing}

Path analysis model was used to test the proposed research hypotheses. Once the research model was developed and data were collected, they were estimated using a set of identified relations between the observed variables. Path analysis models are the rational development of multiple regression models. In path analysis, the presence of any number of dependent and independent variables as well as any number of equation is possible. The significance (P-value) of all the coefficients and parameters of the proposed model was rested in the output of model. To determine the significance of a factor, the p-value must be larger than 1.96 or smaller than -1.96 . The result of path analysis model and significance of path coefficients are shown in figure 5 and 6.

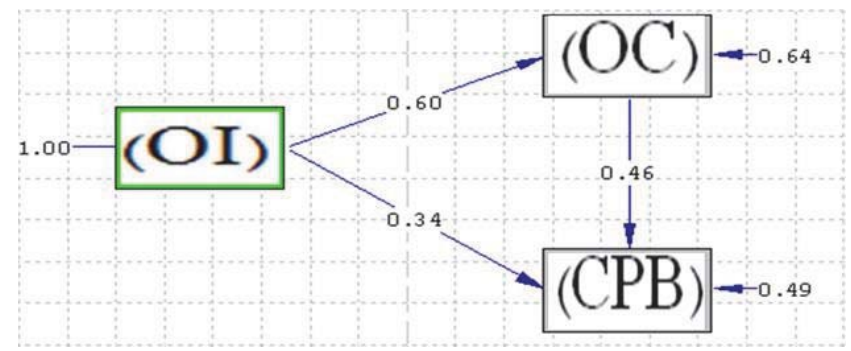

Figure 4: Path analysis model for the main research hypotheses (standard coefficients)

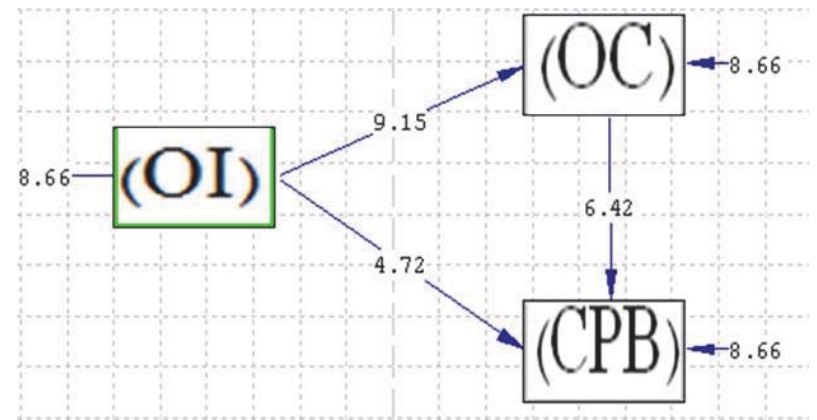

Figure 5: Path analysis model for the main research hypotheses (P-value) 
The following tables are presented for a better illustration of the relationships and values between the parameters of the model (direct and indirect effects).

Table 5: Calculation of direct, indirect and total effects of all dependent and independent variables

\begin{tabular}{|l|l|c|c|c|}
\hline Independent Variable (from) & Dependent Variable (to) & Direct Effect & Indirect Effect & Total Effect \\
\hline \multirow{2}{*}{ Organizational Injustice } & Organizational Cynicism & 0.60 & ----- & 0.60 \\
\cline { 2 - 5 } & Counterproductive Behaviors. & 0.34 & 0.27 & 0.61 \\
\hline Organizational Cynicism & Counterproductive behaviors. & 046 & ---- & 0.46 \\
\hline
\end{tabular}

Table 5 shows that organizational injustice had the highest significant total effect $(0.61)$ on counterproductive behavior while it indirectly $(0.27)$ affects counterproductive behaviors. The summary of path analysis results for all hypotheses is presented in Table 6.

Table 6: The results of standard coefficients and P-value (Confirmation or Rejection of Hypotheses)

\begin{tabular}{|l|l|c|c|c|}
\hline From & To & $\begin{array}{c}\text { Standard } \\
\text { Coefficient }\end{array}$ & P-value & $\begin{array}{c}\text { Confirmation or Rejection } \\
\text { of Hypotheses }\end{array}$ \\
\hline Organizational Injustice (OI) & Organizational Cynicism (OC) & 0.60 & 9.15 & Confirmed \\
\hline Organizational Injustice & Counterproductive Behavior (CPB) & 0.34 & 4.72 & Confirmed \\
\hline Organizational Cynicism & Counterproductive Behaviors. & 0.46 & 6.42 & Confirmed \\
\hline
\end{tabular}

According to Table 6, the standard coefficients for each of the three hypotheses had an acceptable p-value (higher than 1.96); thus, all the research hypotheses were confirmed.

\section{Discussion}

Data analysis of the findings as well as the research hypotheses of the present research briefly is discussed hereunder.

\subsection{First Hypothesis: Organizational cynicism had a significant effect on counterproductive behaviors.}

The standard coefficient between the organizational cynicism and counterproductive behaviors was 0.46 . Also, their $p$ value i.e. 6.42 (higher than 1.96) showed that there was a significant relationship between organizational cynicism and counterproductive behaviors. Therefore, the null hypothesis was rejected and the first hypothesis was confirmed. That is, organizational cynicism increases the likelihood of counterproductive behaviors amongst the employees. The results of the first hypothesis, were consistent with the findings Hassanpour et al. (28), Lasisi et al. (29) and Shahzad (30).

\subsection{Second Hypothesis: Organizational injustice had a significant effect on counterproductive behaviors.}

The standard coefficient between the organizational injustice and counterproductive behaviors was 0.34 . Also, their $p$ value i.e. 4.72 (higher than 1.96) showed that there was a significant relationship between organizational injustice and counterproductive behaviors. Therefore, the null hypothesis was rejected and the first hypothesis was confirmed. That is, organizational injustice increases the likelihood of counterproductive behaviors amongst the employees. The results of the second hypothesis, were line with the findings of Ghovati (31), Pirzadeh (32), Barati et al. (33) and Lasisi et al. (34).

\subsection{Third Hypothesis: Organizational injustice had a significant effect on organizational cynicism.}

The standard coefficient between the organizational injustice and organizational cynicism was 0.60 . Also, their p-value i.e. 9.15 (higher than 1.96) showed that there was a significant relationship between organizational injustice and organizational cynicism. Therefore, the null hypothesis was rejected and the first hypothesis was confirmed. That is, organizational injustice increases the likelihood of organizational cynicism amongst the employees. The results of the third hypothesis, were line with the findings of Chyabrv (34). 


\section{Suggestion and Conclusion}

The results of the current study indicated that not only organizational cynicism but also organizational injustice increase counterproductive behaviors amongst the employees of the intended state hospital. Furthermore, organizational injustice increases organizational cynicism amongst the employees.

According to the first hypothesis, indicating the effect of organizational cynicism on counterproductive behaviors, the managers of state hospitals are recommended to make necessary attempts to reduce counterproductive behaviors amongst their employees so that the organizational cynicism gets decreased. In this regard, the following suggestions are offered:

- One of the main factors causing organizational cynicism is organizational injustice. In order to create organizational justice, it is recommended to eliminate discrimination amongst the employees. If the bylaws, regulations and orientations, in any organization, are discriminatory, the employees get distrustful. Trust is created by improving justice and equity; subsequently, vitality, empowerment and citizenship behaviors develops in the organizational culture. The managers of state hospitals must evaluate employees' perception of organizational justice and identify the weak points of the hospitals in this area in order to improve the perceptions of organizational justice amongst the personnel and, successively reduce their cynicism.

- The present study recommends that the managers of the intended state hospitals adopting an attitude so that their employees be able to figure out justice in each of the its organizational dimensions. Based on the concept justice, a certain procedure, specifically the processes leading to granting bonus and rewards, should be set clear enough to design an overt compensation policy system. So that, each employee is justified that the compensation system is used in a precise and unbiased manner without any prejudice. To properly implement an overt compensation policy system, it requires to administrate its pre requisite system, i.e. the personnel evaluation system, accurately and scientifically beforehand.

- Managers are recommended to hold a variety of meetings to profoundly figure out the causes of organizational cynicism once they observe its signs and outcomes in their organization; and accordingly devise a special plan to eliminate any factor causing cynicism.

- Hospitals are recommended to increase the perception of employees about the organizational supports they provide and, consequently, reduce their cynicism by administrating different supportive programs. In this regard, managers can also demonstrate such behaviors as attention to the needs and interests of employees and respecting their rights in order to reduce organizational cynicism.

- Other influential factors on organizational cynicism are recommended to be identified by conducting different surveys to get them improved in order to reduce organizational cynicism and counterproductive behaviors amongst the employees.

According to the second and third hypotheses, assuming the effects of organizational justice on both organizational cynicism and counterproductive behaviors, the managers of the intended state hospitals are suggested to decline organizational cynicism and counterproductive behaviors by increasing the perception of employees about organizational justice and by reducing injustice. In this regard, the following suggestions are offered to improve organizational justice:

- The employees' perceptions of organizational justice can be improved by granting rewards and benefits as well as providing a favorable working conditions with respect to the performance of employees.

- With respect to the fact that the interaction of managers with employees play an important role in employees' perception of organizational justice, the hospitals can hold training courses for managers in order to improve their supervisory skills, communicative skills and relations with their subordinates so that the employees' perceptions of interactional justice are enhanced. This way, they can help the managers reduce organizational cynicism and counterproductive behaviors amongst the employees.

- Focusing on different aspects of their relationship (attention, respect, etc.), managers can promote employees' perceptions in this area. Also, they should be trained how to use different cooperative, participatory and supportive styles to enhance the employees' perceptions of organizational justice (interactional justice).

- In order to promote justice, managers are recommended to develop a system based on equity and trust. One way of creating trust is implementing methods that make the organization more predictable. However, it depends on two important factors: Clarity and discipline. What makes the organization's communicative network clear and disciplined is being systematic in all of its subsystems including evaluation system, education system, recruitment system, adjustment system, promotion system, and payroll system. 
- The intended hospitals can also conduct several research on organizational justice to identify its influential factors (including personal and organizational) in order to improve them. By improving the influential factors on organizational justice, the perceptions of employees about organizational justice will increase. As a result, the employees' organizational cynicism and counterproductive behaviors will decrease.

In addition to the aforementioned suggestions, the following general recommendations are offered to the managers of state hospitals to reduce organizational cynicism and counterproductive behaviors of their employees.

- Establishing an effective rewarding system to encourage the staff with the least counterproductive behaviors.

- Holding several training courses for the employees about detriments of counterproductive behaviors to not only the organization but also the staff.

\section{Acknowledgement}

A special acknowledgment for the assistance of the Research Department of Tarbiat Modares University in Tehran which for their kind contribution to the present study. It should be noted that this article was retrieved from the master thesis Parisa Abdi.

\section{References}

1-Kisamore, J.L. and Jawahar, I.M. and Liguori, E.W. and Mharapara, T.L. Conflict and abusive workplace behaviors: The moderating effects of social competencies. Career Development International, Vol. 15,2010, 583-600.

2-Nasir, M. Bashir, A. Examining workplace deviance in public sector organizations of Pakistan. International Journal of Social Economics, Vol. 39,2012, 240-253.

3-FitzGerald, M.R. Organizational cynicism: Its relationship to perceived organizational injustice and explanatory style. Dissertation submitted to the Division of Research and Advanced Studies of the University of Cincinnati in partial fulfillment of the requirements for the degree of Doctor of Philosophy in the Department of Psychology of the Graduate School of Arts and Sciences.2002.

4-James, M.S.L. Antecedents and Consequences of Cynicism in organizations: An examination of the potential positive and negative effects on school systems. Dissertation submitted to the Department of Management in partial fulfillment of the requirements for the degree of Doctor of Philosophy, The Florida State University, College of Business.2005.

5-Colbert A.E. and Mount, M.K. and Harter, J.K. and Witt L.A. and Barrick, M.R. Interactive Effects of Personality and Perception of the Work Situation on Workplace Deviance. Journal of Applied Psychology, Vol. 89,2004, 599-609.

6-Spector, P.E. and Fox, S.The stressor-emotion model of counterproductive work behavior. In S. Fox \& P. E. Spector (Eds.), Counterproductive work behavior: Investigations of actors and targets (2005, 151-174). Washington, DC: American Psychological Association.

7-Gallagher, E.C. Narcissism and forgiveness as moderators of organizational justice and workplace counterproductive computer use. Thesis for the Degree Master of Arts, University of Nebraska. 2009.

8- Golparvar, M. \& Khaksar, S. (2008). Counterproductive Behaviors from the Perspective of Supervisors, Industrial and Organizational Managers. Journal of Ethics in Science and Technology, (3)4, $18-26$.

9-Galperin B.L. and Burke, R.J. Uncovering the relationship between workaholism and workplace destructive and constructive deviance: An exploratory study. International Journal of Human Resource Management, Vol. 17,2006, 331-347.

10-Muafi, D. Causes and Consequence Deviant Workplace Behavior. International Journal of Innovation, Management and Technology, Vol. 2011, 123-126

11-Cartwright, S. and Holmes, N. The meaning of work: The challenge of regaining employee engagement and reducing cynicism. Human Resource Management Review, Vol. 16,2006, 199-208.

12-Kalagan, G. and Aksu, B. Organizational cynicism of the research assistants: A Case of Akdeniz University. Procedia Social and Behavioral Sciences, Vol. 2,2010, 4820-4825.

13- Javadin, R., Frahai, M. \& Taheri, G. (2008). Identifying the Impact of Different Dimensions of Organizational Justice on Various Aspects of Job Satisfaction and Organization. Business Management, (1), 55-70.

14- Yaghubi, M., Saghaeian. S., Gorji, H., Noruzi, M. \& Rezaei, F. (2009). The Relationship Between Organizational Justice and Job Satisfaction and Organizational Commitment of Personnel in Selected Hospitals of Isfahan University of Medical Sciences. Journal of Health Administration (35), 25-32.

15- Brown, M. and Cregan, C.(2008). Organizational change cynicism: The role of employee involvement. Human Resource Management, Vol. 47, pp. 667-686.

16- Handlon, R L. The departure of the insurance agent: The impact organizational commitment, organizational justice, and job satisfaction have on intent to leave in the insurance industry, CAPELLA UNIVERSITY, 2009, 179

17- Alinejad V, Shadmehr A, kazemi Asfeh Sh, Gholizade R, Tabbakhi E. Examine the Relationship Between Organizational Citizenship Behavior and Organizational Health in Specialty and Subspecialty Seyyed-al-Shohada Hospital Staff, Urmia. The Social Sciences. 2016 , Volume: 11 , Issue: 6, Page No.: 910-917 DOI: 10.3923/sscience.2016.910.917. 
18- Alinejad V, Shadmehr A, Investigation of the Factors Affecting the Positivity of the Transplant Result. The Social Sciences. 2016 , Volume: 11 , Issue: 6, Page No.: 906-909 DOI: 10.3923/sscience.2016.906.909

19- Farrokh-Eslamlou $\mathrm{H}$, Oshnouei S, Alinejad V. Novel restricted access to vasectomy in Iran: addressing changing trends in vasectomy clients' characteristics over 16 years in northwestern Iran. Contraception. 2015 Nov;92(5):488-93. doi: 10.1016/j.contraception. 2015.07.010. Epub 2015 Jul 28.

20- Hosseinlou A, Alinejad V, Alinejad M, Aghakhani N. The effects of fish oil capsules and vitamin B1 tablets on duration and severity of dysmenorrhea in students of high school in Urmia-Iran. Glob J Health Sci. 2014 Sep 18;6(7 Spec No):124-9.doi: 10.5539/gjhs.v6n7p124.

21- Khademvatan K, Alinejad V, Eghtedar S, Rahbar N, Agakhani N. Survey of the relationship between metabolic syndrome and myocardial infarction in hospitals of Urmia University of medical sciences. Glob J Health Sci. 2014 Sep 18;6(7 Spec No):58-65. doi: 10.5539/gjhs.v6n7p58.

22- Alinejad V, Mahmodi M, Alinejad M, Besharat E, Gholizade R, Tabbakhi E, Shojaei Pour A, Gharaaghaji R. Investigation of long- and short-term relationships between cesarean delivery and its effective factors in Malayer. Glob J Health Sci. 2014 Sep 18;6(7 Spec No):1-7. doi: 10.5539/gjhs.v6n7p1.

23- Niknejad E, Alinejad V ,Samarei R, The Review of Factors Affecting the Hospitalization Period of Patients with Fractures under the Age of 10. Research Journal of Medical Sciences2016 , Volume: 10 , Issue: 2 , Page No.: 32-35. DOI: 10.3923/rjmsci.2016.32.35

24- Niknejad E, Alinejad, Factors Affecting the Duration of Decay of the First Permanent Molar Tooth. Research Journal of Medical Sciences2016, Volume: 10 , Issue: 2 , Page No.: 36-38 DOI: 10.3923/rjmsci.2016.36.38

25-Rahimi-Rad MH, Eishi A. Superior vena cava syndrome in a man with situs inversus totalis and left main bronchus cancer. Pneumologia. 2009 Jan-Mar;58(1):52-4.

26-Eishi A, Rahimi E, Akhavan S, Shahgaibi S, Fariba F. Cancer during pregnancy: a review of 10 years of experience. Pak J Biol Sci. 2012 Apr 1;15(7):341-6.

27-Rahimi-Rad MH, Asgari B, Hosseinzadeh N, Eishi A. Eosinopenia as a Marker of Outcome in Acute Exacerbations of Chronic Obstructive Pulmonary Disease. Maedica (Buchar). 2015 Mar;10(1):10-3.

28- Hasanpour, A., Nouri, R. \& Kiaei, M. (2009). Organizational Cynicism: Causes and Consequences. Management Culture, (19), 119142.

29-Lasisi, O.J. and Okuneye, M.Y. and Shodiya, O.A. Antecedents of counter work behavior in public sector organizations: evidence from nigeria. Kuwait Chapter of Arabian Journal of Business and Management Review, Vol. 3, 2014. 58-65.

30-Shahzad, A. and Mahmood, Z. The Mediating - Moderating Model of Organizational Cynicism and Workplace Deviant Behavior: (Evidence from Banking Sector in Pakistan). Middle-East Journal of Scientific Research, Vol. 12,2012, 580-588.

31- Ghovati, F. (2014). The Relationship Between Organizational Support, Organizational Justice and Counterproductive Behaviors of Staff at the University of Mahshahr. A Master Thesis. Islamic Azad University, Khuzestan Science and Research Branch.

32- Pirzade, N. (2013). The Relationship Between Perceived Organizational Justice and Organizational Citizenship Behavior and Counterproductive Behavior amongst the staff in Kharg Island Oil Terminal. A Master Thesis. Islamic Azad University, Marvdasht Branch.

33- Barati, H., Arizi, H., Barati, A., Sarhangi, K. \& Ranjbar, H. (2013). The Impact of Organizational Justice and Organizational Climate on Counterproductive Behaviors. Journal of Organizational Culture Management (30), 181-197.

34 -Chiaburu, D.S. and Peng, A.C. and Oh, I.S. and Banks, G.C. and Lomeli, L.C. Antecedents and consequences of employee organizational cynicism: A meta-analysis. Journal of Vocational Behavior, Vol. 83,2013, 181-197 